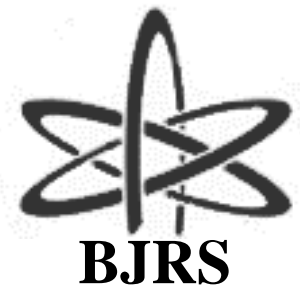

BRAZILIAN JOURNAL

$\mathrm{OF}$

RADIATION SCIENCES

09-01A (2021) 01-13

\title{
Appreciation of influence of acquisition parameters in analysis of root canal using microCT system
}

\author{
Bastos $^{a}$ L.F., de Araujo ${ }^{a}$ O.M.O., Santos ${ }^{a}$, C.M.S.F.F., Teixeira ${ }^{a}$, T.P., Funcke ${ }^{a}$, \\ R.P.N., de Lima ${ }^{a}$, J.C.R., Machado ${ }^{a}$, A.S., Oliveira ${ }^{a}$, D.F., Lopes ${ }^{a}$, R.T. \\ ${ }^{a}$ Nuclear Instrumentation Laboratory/Federal University of Rio de Janeiro/P.O Box 68509, 21941-972, Rio de Janeiro, \\ RJ, Brazil \\ luanfbastos@gmail.com
}

\begin{abstract}
Microtomography is successfully used in the odontological evaluation and treatments, as it's capable to analyze the bone tissue and any possible damage in its root canal caused by a surgical intervention. In this study, the microCT was used to analyze the images by using different parameters in the acquisition process, as two matrix sizes: 1120x1120 pixels and 2240x2240 pixels. After the reconstruction, the volume of the root canal was analyzed, as well as the quantification of a remaining tooth closure material. The results showed that the detector array $1120 \times 1120$ was able to capture values close to those of the $2240 \times 2240$ matrix for the volume of root canal and for the residual material after treatment. Remaining tooth closure material correspond an average of 0.95 $\mathbf{m m}^{3}$ for $1120 \times 1120$ pixels, while the corresponding volume for $2240 \times 2240$ pixels was $0.90 \mathbf{~ m m}^{3}$. Results for root canal volume average was $10.32 \mathrm{~mm}^{3}$ for $1120 \times 1120$ pixels, while for $2240 \times 2240$ pixels was $10.22 \mathrm{~mm}^{3}$. In this way, the difference of the detected volume between the two matrices is of $5.47 \%$ for the residual material and $0.93 \%$ for root canal volume. In a qualitative analyze, the $2240 \times 2240$ matrix allows the identification of a greater amount of details. However, it was possible to verify that depending on the application and the region of interest studied the smaller matrix can offer reliable results and a shorter processing time.
\end{abstract}

Keywords: microtomography, parameter comparison, root canal study. 


\section{INTRODUCTION}

The use of X-ray microtomography system has been widely accepted in the study of dental applications. This technique has been applied especially in the study before and after the interventions performed in the root canal, because its non-destructive characteristic allows analyzing the occurrence of some injury on the wall during the treatment or not complete removal of some material used during the surgical intervention. The results of researches in endodontics have shown excellent progress in diagnoses, to improve the technique and to identify the damages caused by pathologies and dental interventions.

In order to achieve optimum image quality during acquisition, several factors must be considered, such as the voltage and current applied to the X-ray source, the use of filters that block the low energy photons from reaching the scanned object, the resolution of the system, the image matrix, the pitch of the rotation and the rotation of the object around its own axis. There is lots of study that used close parameters, but a higher resolution can be found with a microCT.

Papers have used near acquisition parameters, but the same matrix of detector. Pixel size depends generally the size of studied object, and the matrix of detector array 1120x1120 is widely used. Thus, this work aims to compare the variation of pixel size and detector array, while the other parameters remain constant, so that optimize the quantitative and qualitative analysis performed for the study of root canals.

A study comparing different instruments of the root canal and which caused a greater accumulation of debris was possible with microCT. In canals with a high prevalence of isthmuses and protrusions, using multifile rotary systems may be preferred over reciprocating files because it can yield cleaner canals with less debris accumulation [1].

A three-dimensional comparison was made regarding the volume and surface area of the root canals before and after instrumentation and verified the transport of materials and changes in the geometry of the apical third. MicroCT demonstrated that the instrumentation used for the preparation of the channel was satisfactory [2]. 
A routine mechanism for image processing to quantify volumes, debris resulting from procedures and areas of difficult root canal access regions was proposed to guide studies with the use of free software [3].

A microCT system was used for the comparison of different instrumentations for the treatment of root canals. Analysis showed that the procedures performed left a residual material in the root canals [4].

The quantitatively evaluate root canal fillings after commonly used endodontic procedures could be done with microCT. The system showed to be a useful tool for this kind of works and was possible to quantify the numbers of voids in the filling material [5].

MicroCT system compares two different instrumentations to determine the more efficient. It was possible to notice that after the instrumentation, some teeth presented residual material in the root canal and the microCT made it possible to identify them to instrument again. In this way, microCT became essential to make a better comparison between the two systems [6].

An evaluation of probable dental damage, such as micro cracks, due to procedures in the preparation of root canals was possible through the application of microCT. The work concluded that the instrumentation used did not cause damages in the samples [7].

The frequency of dental micro cracks, observed as a result of the preparation of the root canal during different procedures, in mandibular incisors can be evaluated through the application of microCT. The research concluded that the techniques used did not cause further damage [8].

The microCT compared the before and after procedures for the preparation of the root canal of maxillary molars through the use of rotational systems. The work showed that the jobs of the instrumentation used did not present any considerable difference [9].

A study to evaluate the instrumentation of root canal in maxillary primary central incisor was performed with the use of microCT [10]. The main difference in this study in relation to the others was that the authors used a $2240 \times 2240$ detector array to study the procedure performed.

A study on the mesial root canal morphology of the Brazilian population can be performed with the application of microCT. The study showed a high morphological differentiation [11].

A microCT system was used to assess the effectiveness of modern endodontic shaping and filling procedures on mesiobuccal roots of maxillary molars with two canals. The analysis were carried out prior to treatment, after canal shaping and after canal filling to determine the alterations 
of the canal volume before and after the instrumentation, the volume of the hard tissue debris, and percentage of the volume occupied by filling materials. The study demonstrated that the instrumentation could be partially effective for the treatment of the mesiobuccal canals and their accessory endodontic structures [12].

An X-ray microtomography system was used to study the shaping ability of four instrumentation systems in curved root canals of mandibular molars. The teeth underwent a scanning process before and after the instrumentation and a quantity analysis was realized to determinate the effectiveness of instrumentation methods [13].

\section{MATERIALS AND METHODS}

The study used a tooth after a canal treatment that left a remaining material. The choice was made in order to allow the comparison of different acquisition parameters of microCT and how they would affect the analysis. A digital caliper was used to define tooth dimensions. The tooth is 15.71 $\mathrm{mm}$ vertically and $7.34 \mathrm{~mm}$ as the greatest horizontal value.
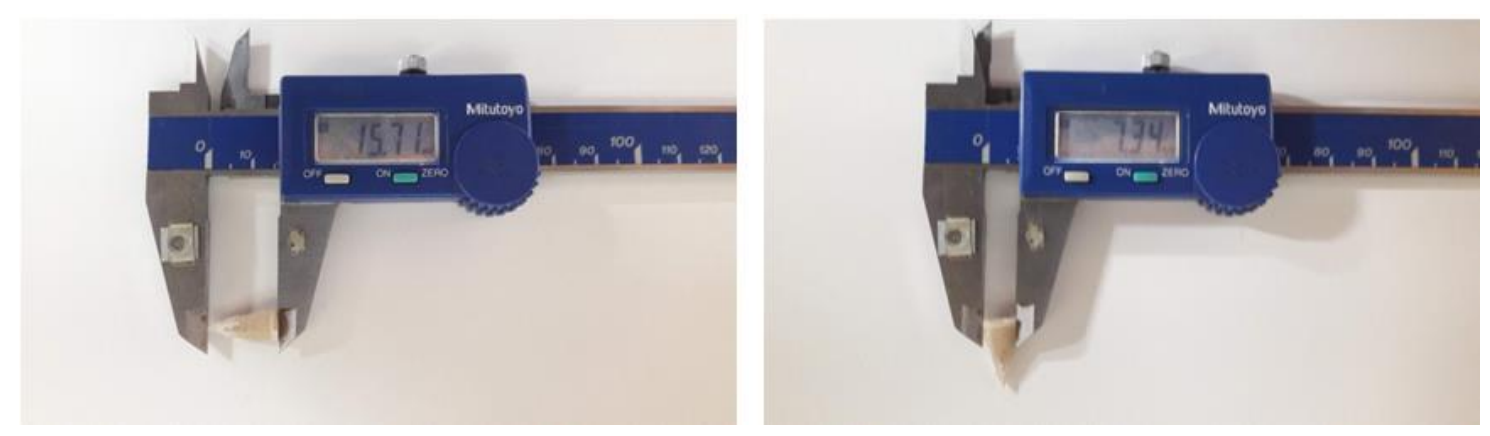

Figure 1: Dimensions of the studied tooth.

To realize this study, the X-ray microtomography system - Skyscan-Bruker model 1173 - was used. That is a benchtop microtomography system with a minimum image pixel size of $5 \mu \mathrm{m}$. The microfocus X-ray source can operate with a maximum voltage of $130 \mathrm{kV}$ and maximum electric power of $8 \mathrm{~W}$. The position of the X-ray source and the detector are fixed. 
Pixel sizes used were chosen in a manner that the distance between the source and the object remained constant and the ratio between the pixel sizes for the different matrices is $2: 1$. In this way, four pairs were made so that the qualitative analysis could compare images with the same distance between the object and the source. The pairs were defined as follows: $7.8 \mu \mathrm{m}$ and $15.6 \mu \mathrm{m} ; 8.55 \mu \mathrm{m}$ and $17.1 \mu \mathrm{m} ; 9.95 \mu \mathrm{m}$ and $19.9 \mu \mathrm{m} ; 15.6 \mu \mathrm{m}$ and $31.2 \mu \mathrm{m}$ (the values for the $2240 \times 2240$ detector array were presented before the values for the 1120x1120).

The pixel size is related to the magnification used in tomography. In this way, the pair of $7.8 \mu \mathrm{m}$ and $15.6 \mu \mathrm{m}$ occurs when the tooth is at the shortest distance to the X-ray source so that it occupies the entire projection area. The pair of $15.6 \mu \mathrm{m}$ and $31.2 \mu \mathrm{m}$ is when the tooth is at the shortest distance to the detector. The detector matrix is defined as the smallest information of a cell array can store. When the $1120 \times 1120$ matrix is used, it means that two cells of the $2240 \times 2240$ detector array work together. Each cell represents the smallest size of information detectable by the detector. When the pixel size of $7.8 \mu \mathrm{m}$ was used, it means that the information contained in that cell represents a detail of $7.8 \mu \mathrm{m}$ of the object. It is expected that the $2240 \times 2240$ matrix presents a greater diversity of information.

Experiments were executed with following parameters: $70 \mathrm{kV}, 114 \mu \mathrm{A}, 8 \mathrm{~W}$, rotation step of $0.50^{\circ}$, a rotation of $360^{\circ}$ and $1.0 \mathrm{~mm}$ aluminum filter. Two matrix sizes were used: $1120 \times 1120$ pixels (with effective pixel size of $15.6 \mu \mathrm{m}, 17.1 \mu \mathrm{m}, 19.0 \mu \mathrm{m}$ and $31.2 \mu \mathrm{m}$ ) and 2240x2240 pixels (with effective pixel size of $7.8 \mu \mathrm{m}, 8.55 \mu \mathrm{m}, 9.95 \mu \mathrm{m}$ and $15.6 \mu \mathrm{m}$ ). With the software of the manufacturer, it was possible to perform the image processing. The acquisition time for 1120x 1120 matrix took around 20 minutes while for the 2240x2240 matrix took over than 1 hour.

\subsection{Image Processing}

The reconstruction of images was performed with the software from the system manufacturer, InstaRecon ${ }^{\circledR}$, v. 1.7.3.0. The software allowed the correction of the following parameters: Smoothing, Misalignment compensation, Beam hardening and Ring artifacts.

CTAn, v. 1.18.4.0, was the software used for binarization and analysis of the remaining materials in the canal and root canal volume and compare the results obtained by changing the acquisition parameters. The use of CTAn allowed the quantitative analysis of the objects of study. 
DataViewer, v. 1.5.4.6 software was used to generate the different views. With the use of this software it was possible to evaluate how the changes in the detector matrix affects the qualitative analyzes of the reconstructed images of the remaining material in the tooth canal and the volume of the root canal.

\section{RESULTS AND DISCUSSION}

$\mathrm{X}$-ray microtomography system is known as a powerful non-destructive tool and it's utilization in teeth samples is very disseminated around the world. This study has the objective to determinate the best acquisition parameters to obtain best results for odontology studies.

Quantitative analysis shows a small difference for 1120x1120 and 2240x2240 matrices for voids volume, for residual material and for canal root volume, as shown in table 1.

Table 1: Percentage of volumes identified for the residual material and canal root volume

\begin{tabular}{ccccc}
\hline Matrix & $\begin{array}{c}\text { Pixel Size } \\
(\mu \mathrm{m})\end{array}$ & $\begin{array}{c}\text { Residual Material } \\
\left(\mathrm{mm}^{3}\right)\end{array}$ & $\begin{array}{c}\text { Voids Volume } \\
\left(\mathrm{mm}^{3}\right)\end{array}$ & $\begin{array}{c}\text { Canal Root Volume } \\
\left(\mathrm{mm}^{3}\right)\end{array}$ \\
\hline $1120 \times 1120$ & 15.6 & 0.94 & 9.33 & 10.27 \\
\hline $1120 \times 1120$ & 17.1 & 0.94 & 9.53 & 10.46 \\
\hline $1120 \times 1120$ & 19.9 & 0.93 & 9.51 & 10.44 \\
\hline $1120 \times 1120$ & 31.2 & 0.98 & 9.12 & 10.37 \\
\hline $2240 \times 2240$ & 7.8 & 0.87 & 9.50 & 10.22 \\
\hline $2240 \times 2240$ & 8.55 & 0.88 & 9.34 & 10.30 \\
\hline $2240 \times 2240$ & 9.95 & 0.89 & 9.40 & 10.00 \\
\hline $2240 \times 2240$ & 15.6 & 0.95 & 9.05 & \\
\hline
\end{tabular}

Table 1 allows analyzing the volume of residual material and voids volume for the different pixel sizes. When comparing the pixel size pairs, it is possible to notice that it was not possible to identify any significant difference for the values of the residual material and for the voids of the canal root volume. 
It is also possible to compare the same pixel size, but in different matrices for the $15.6 \mu \mathrm{m}$. When comparing the results, it was not possible to notice any significant difference.

Table 2 shows the average of residual material and for root canal volumes for each detector array and through it is possible to determine the deviation to the values determined by the microCT. The residual material showed a deviation of $5.47 \%$, which is considered a low value to measurement of any material present in the root canal. When the deviation for the root canal volume is analyzed, a value of $0.93 \%$ is found, which is not significant.

Table 2: Percentage of average for residual material and for root canal volumes

\begin{tabular}{ccc}
\hline Matrix & Average for Residual Material $\left(\mathrm{mm}^{3}\right)$ & Average for Root Canal Volume $\left(\mathrm{mm}^{3}\right)$ \\
\hline $1120 \times 1120$ & 0.95 & 10.32 \\
\hline $2240 \times 2240$ & 0.90 & 10.22 \\
\hline
\end{tabular}

The qualitative analyzes differences in the views generated by the DataViewer software. In figures 2 and 3 is possible to notice how the instrumentation affected canal root wall, which caused the appearance of cracks that are inside the red circle. The $2240 \times 2240$ matrix showed more details than the other. The smallest pixel size $(7.8 \mu \mathrm{m})$ allowed the visualization of more detailed cracks, mainly better definition of the edges.

When the comparison is made between the $15.6 \mu \mathrm{m}$ pixel size in different matrices, it is possible to notice that in this case the $1120 \times 1120$ matrix presents a greater richness of details. All comparisons between the pairs showed the best visualization for the $2240 \times 2240$ matrix. 
$1120 \times 1120$ matrix

a)

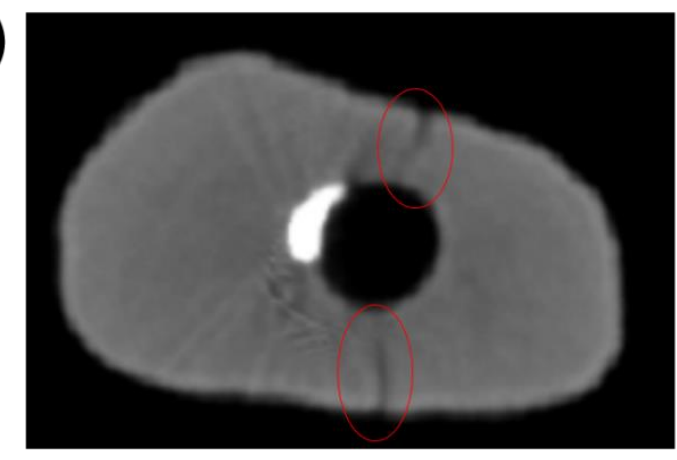

b)

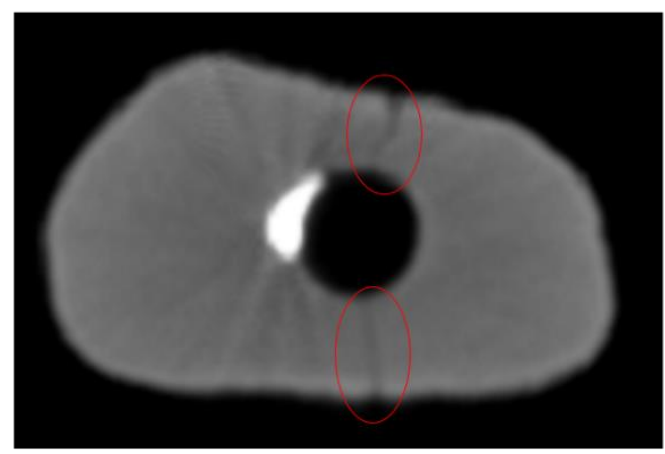

c)

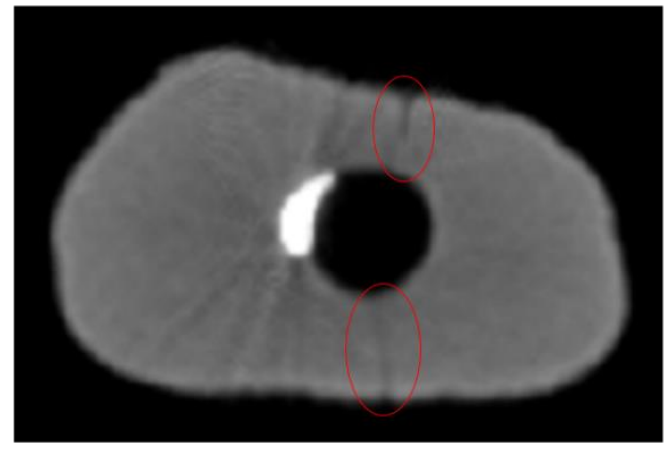

d)

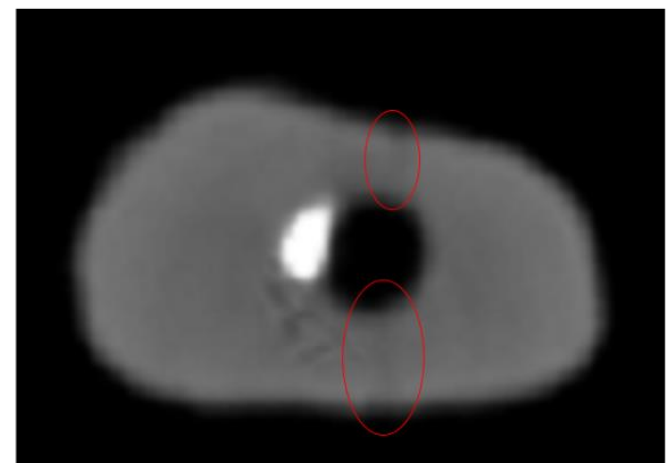

$2240 \times 2240$ matrix
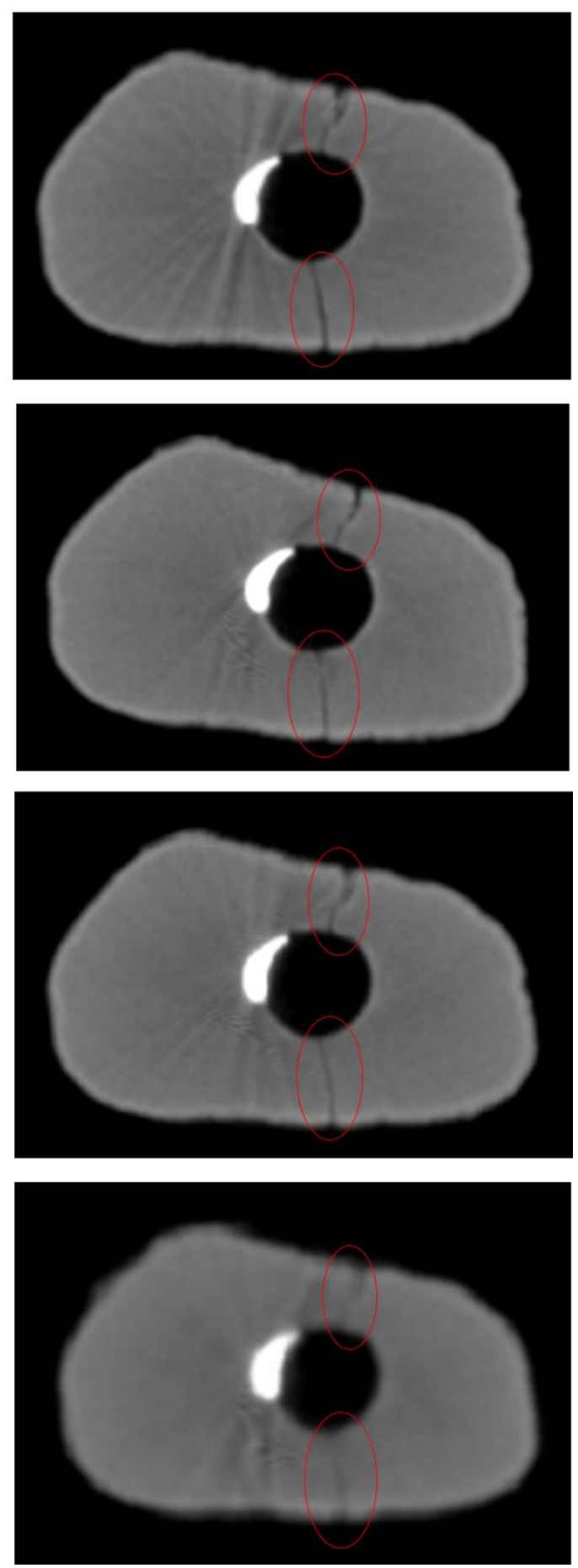

Figure 2: Transaxial view for differents pixels for $1120 \times 1120$ and $2240 \times 2240$ matrices. a) effective pixel size of 15.6 and $7.8 \mu \mathrm{m} ; b$ ) effective pixel size of 17.1 and $8.55 \mu \mathrm{m} ; \mathrm{c}$ ) effective pixel size of 19.9 and $9.95 \mu \mathrm{m} ; d)$ effective pixel size of 31.2 and $15.6 \mu \mathrm{m}$; 
$1120 \times 1120$ matrix

a)

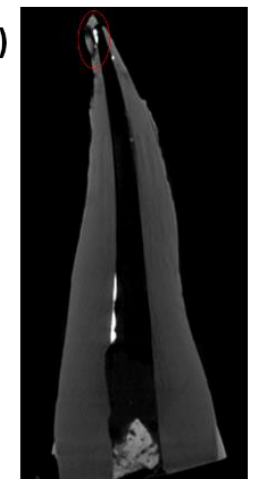

b)

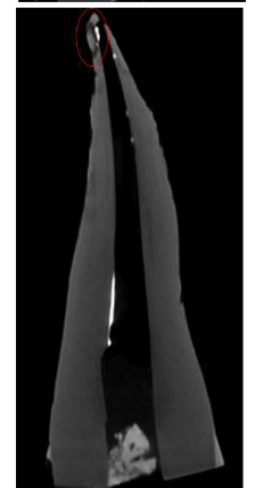

c)

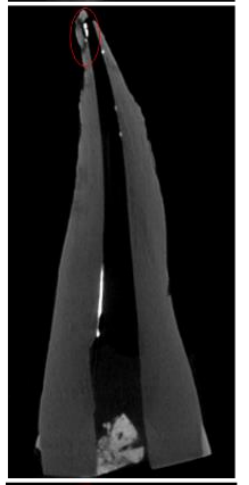

d)

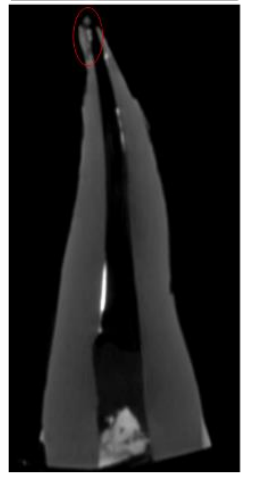

2240x2240 matrix
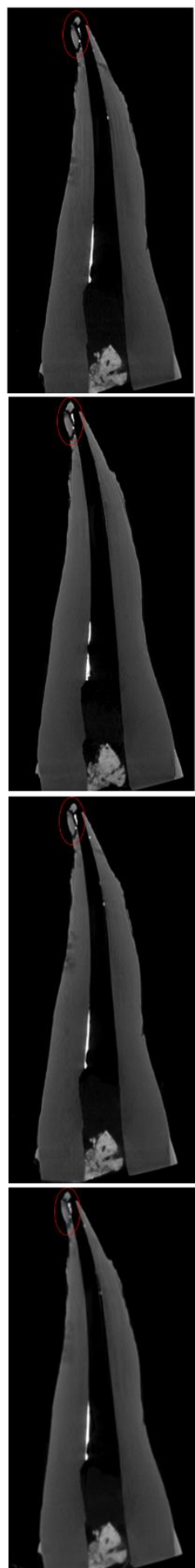

Figure 3: Coronal view for differents pixels for $1120 \times 1120$ and $2240 \times 2240$ matrices. a) effective pixel size of 15.6 and $7.8 \mu \mathrm{m}$; b) effective pixel size of 17.1 and $8.55 \mu \mathrm{m}$; c) effective pixel size of 19.9 and $9.95 \mu \mathrm{m} ; d)$ effective pixel size of 31.2 and $15.6 \mu \mathrm{m}$; 


\section{CONCLUSION}

The quantitative analysis did not present any significant difference when the 1120x1120 and $2240 \times 2240$ matrices were used for the determination of the volume occupied by the root canal and by the residual material.

The qualitative analysis presented significant differences when the different views are compared to each other. The cracks showed in the root canal wall were more detailed when the $2240 \times 2240$ matrix is used. When the same pixel $(15.6 \mu \mathrm{m})$ size was compared in different matrices, was possible to notice that the $1120 \times 1120$ matrix showed more details than 2240x2240 matrix. Thus, the use of the $2240 \times 2240$ matrix is most recommended when it is necessary to obtain visual details, to perform a qualitative analysis of the material and when it is necessary to analyze if the instrumentation caused any damage along the channel.

The use of the different matrices meets the expectations when the analysis is performed. The quantitative analysis did not show any significant differences, while the qualitative analysis showed. When it is necessary to analyze only the volume of material and of root canal, the study showed no differences for the choice of matrices. If it is necessary to make a qualitative analysis, it is suggested to use the $2240 \times 2240$ matrix, even though a longer acquisition time is necessary.

It is suggested a study that vary other parameters to identify the influence that may occur for measuring a residual material in the root canal. 


\section{ACKNOWLEDGMENT}

This study was financed in part by the Coordenação de Aperfeiçoamento de Pessoal de Nível Superior - Brasil (CAPES) - Finance Code 001. The authors also would like to thank to the Conselho Nacional de Desenvolvimento Científico e Tecnológico (CNPq) and Fundação de Amparo à Pesquisa do Estado do Rio de Janeiro (FAPERJ) for the financial support.

\section{REFERENCES}

[1] Robinson, J. P; Lumley, P. J; Cooper, P. R; Grover, L. M; Walmsley, A. Damien. Reciprocating Root Canal Technique Induces Greater Debris Accumulation Than a Continuous Rotary Technique as Assessed by 3-Dimensional Micro-Computed Tomography. Journal of Endodontics, v. 39(8), pp. 1067-1070, 2013.

[2] Almeida, B. C; Ormiga, F; de Araújo, M. C. P; Lopes, R. T; Lima, I. C. B; dos Santos, B. C; Gusman, H. Influence of Heat Treatment of Nickel-Titanium Rotary Endodontic Instruments on Apical Preparation: A Micro-Computed Tomographic Study. Journal of Endodontics, v. 41(12), pp. 2031-2035, 2015.

[3] Neves, A. A; Silva, E. J; Roterm, J. M; Belladona, F. G; Alves, H. D; Lopes, R. T; Paciornik, S; De-Deus, G. A. Exploiting the potential of free software to evaluate root canal biomechanical preparation outcomes through micro-CT images. International Endodontic Journal, v. 48(11), pp. 1033-1042, 2015.

[4] De-Deus, G; Belladonna, F. G; Silva, E. J. N. L; Marins, J. R; Souza, E. M; Perez, R; Lopes, R. T; Versiani, M. A; Paciornik, S; Neves, A. A. Micro-CT Evaluation of Non-instrumented Canal Areas with Different Enlargements Performed by NiTi Systems. Brazilian Dental Journal, v. 26(6), pp. 624-629, 2015.

[5] Kierklo, A; Tabor, Z; Pawinska, M; Jaworska, M. A Microcomputed Tomography-Based Comparison of Root Canal Filling Quality following Different Instrumentation and Obturation Techniques. Medical Principles and Pratice, v. 24(1), pp. 84-91, 2015. 
[6] Alves, F. R. F; Marceliano-Alves, M. F; Sousa, J. C. N; Silveira, S. B; Provenzano, J. C; Siqueira, J, F. Removal of Root Canal Fillings in Curved Canal Using Either Reciprocating Single- or Rotary Multi-instrument Systems and a Supplementary Step with the XP-Endo Finisher. Journal of Endodontics, v. 42(7), pp. 1114-1119, 2016.

[7] De-Deus, G; Carvalhal, J. C. A; Belladonna, F. G; Silva, E. J. N. L; Lopes, Lopes, R. T; Moreira Filho, R. E; Souza, E. M; Provenzano, J. C; Versiani, M. A. Dentinal Microcrack Development after Canal Preparation: A Longitudinal in Situ Micro-computed Tomography Study Using a Cadaver Model. Journal of Endodontics, v. 43(9), pp. 1553-1558, 2017.

[8] Zuolo, M. L; De-Deus, G; Belladonna, F. G; Silva, E. J. N. L; Lopes, R. T; Souza, E. M; Versiani, M. A; Zaia, A. A. Micro-computed Tomography Assessment of Dentinal Microcracks after Root Canal Preparation with TRUShape and Self-adjusting File Systems. Journal of Endodontics, v. 43(4), pp. 619-622, 2017.

[9] Al-Dameh, A; Braga, T; Love, R. M; de Camargo, J. M. P; Alcalde, M. P. Microcomputed tomography evaluation of maxillary molars mesiobuccal canal preparation using BioRaCe and AlphaKite rotary NiTi systems. Dental Press Endodontics, v. 8(2), pp. 29-35, 2018.

[10] Moraes,R. R; Santos, T. M. P; Marceliano-Alves, M. F; Pintor, A. V. B; Lopes, R. T; Primo, L. G; Neves, A. A. Reciprocating instrumentation in a maxillary primary central incisor: A protocol tested in a 3D printed prototype. International Journal of Pediatric Dentistry, v. 29(1), pp. 50-57, 2019.

[11] Marceliano Alves, M. F; Lima, C. O; Bastos, L. G. P. M. N; Bruno, A. M. V; Vidaurre, F; Coutinho, T. M; Fidel, S. R; Lopes, R. T. Mandibular mesial root canal morphology using micro-computed tomography in a Brazilian population. Australian Endodontic Journal, v. 45(1), pp. 51-56, 2019.

[12] Angerame, D; De Biasi, M; Brun, F; Turco, G; Franco, V. Computed microtmography study of untreated, shaped and filled mesiobuccal canals of maxillary first molars. Australian Endodontic Journal, v. 45(1), pp. 72-78, 2019.

[13] Stringheta, C. P; Bueno, C. E. S; Kato, A. S; Freire, L. G; Iglecias, E. F; Santos, M; Pelegrine, R. A. Micro-computed tomographic evaluation of the shaping ability of four 
instrumentation systems in curved root canals. International Endodontic Journal, v. 52(6), pp. 908-916, 2019. 